\title{
Endoscopic ultrasound-guided drainage and necrosectomy of walled-off pancreatic necrosis using a metal stent with an electrocautery- enhanced delivery system and hydrogen peroxide
}

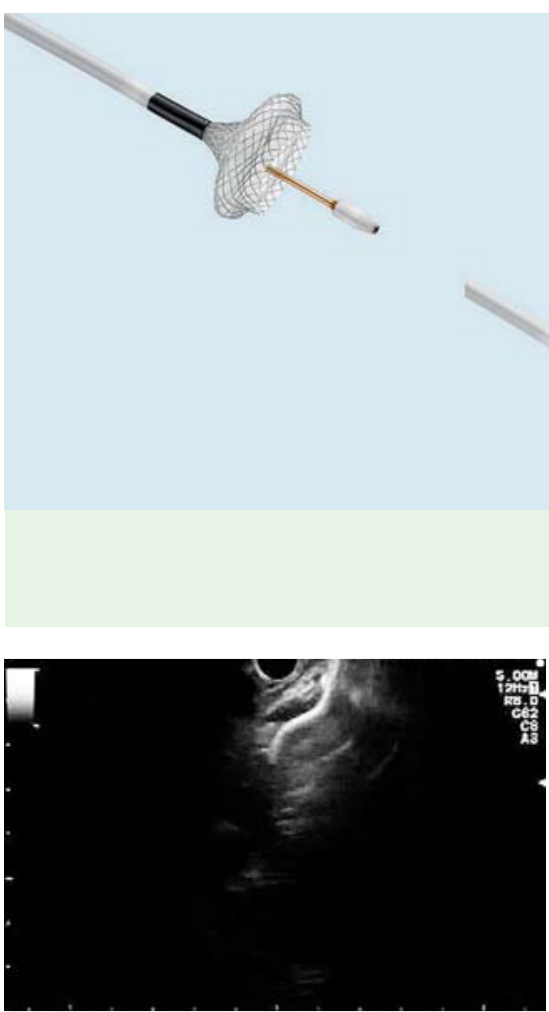

Fig. 2 Endoscopic ultrasound (EUS) image of the distal flange of the self-expanding metal stent being released under EUS guidance.

Direct endoscopic necrosectomy of walled-off pancreatic necrosis (WOPN) has recently been reported to have comparable success rates to surgery, but with lower morbidity and mortality $[1,2]$. The procedure is, however, time consuming and requires multiple device exchanges [3], which may increase the risk of complications.

A novel, dedicated device, the Hot AXIOS (Xlumena Inc., Mountain View, California, USA) ( Fig. 1), has recently become available. This consists of a large-diameter, fully covered self-expanding metal stent (FCSEMS) with antimigration flanges, which is mounted on a 10.8 -Fr delivery system with an electrocautery blade at its distal tip.

We performed endoscopic ultrasound (EUS)-guided drainage of a WOPN (median size $17 \mathrm{~cm}$, range $10-20 \mathrm{~cm}$ ) in four patients using the Hot AXIOS to directly create a transmural fistula, enter the
Fig. 1 A novel throughthe-scope, fully covered, self-expanding metal stent (FCSEMS) delivery system with an electrocautery blade at the distal tip. The Hot AXIOS system allows a cystenteric fistula to be created and the FCSEMS (bottom right) to be delivered without the need for device exchange. (Image courtesy of Xlumena Inc., Mountain View, California, USA.) cavity, and place a $15-\mathrm{mm} \times 10-\mathrm{mm}$ FCSEMS, which was completely deployed under real-time EUS guidance ( $\bullet$ Fig. 2 ).

A standard gastroscope was then used to perform balloon dilation of the lumen of the FCSEMS up to $15 \mathrm{~mm}$ to allow entry into the cavity and perform direct endoscopic necrosectomy. Preliminary data have suggested that irrigation of the necrotic content of areas of WOPN with hydrogen peroxide $\left(\mathrm{H}_{2} \mathrm{O}_{2}\right)$ can facilitate necrosectomy $[4,5]$, so we injected $40-$ $60 \mathrm{~mL}$ hydrogen peroxide (3\%) into the cavity at the beginning and at the end of each session of direct endoscopic necrosectomy. We then used extraction nets, baskets, and forceful irrigation to clean the necrotic material ( $\bullet$ Video 1 ).

The four patients underwent a median of five endoscopy sessions (range 4-6). A pneumoperitoneum occurred in one patient and was treated conservatively. The FCSEMSs were easily removed in three patients. In the remaining patient, who did not present for follow-up until 138 days after insertion of the FCSEMS, over-

\section{Video 1}

An area of walled-off pancreatic necrosis (WOPN) is drained using the Hot AXIOS delivery system under endoscopic ultrasound and endoscopic guidance only. A standard gastroscope is then inserted into the cavity of the WOPN and direct endoscopic necrosectomy is performed. Finally, the stent is removed using an endoscopic snare. growth of normal mucosa had occurred and a decision was made to leave the stent permanently in place.

No recurrence of WOPN has been observed after a mean follow-up of 8.5 months (range 5-10 months).

\section{Endoscopy_UCTN_Code_TTT_1AS_2AD}

Competing interests: Dr. Alberto Larghi is a consultant for Xlumena Inc., Mountain View, California.

\section{Domenico Galasso ${ }^{1}$, Todd H. Baron ${ }^{2}$, Fabia Attili ${ }^{1}$, Khaled Zachariah', Guido Costamagna ${ }^{1}$, Alberto Larghi ${ }^{1}$}

${ }^{1}$ Digestive Endoscopic Unit, Catholic University, Rome, Italy

2 Division of Gastroenterology and Hepatology, University of North Carolina School of Medicine, Chapel Hill, North Carolina, USA

\section{References}

1 Bakker OJ, van Santvoort HC, van Brunschot S et al. Endoscopic transgastric vs surgical necrosectomy for infected necrotizing pancreatitis: a randomized trial. JAMA 2012; 307: 1053-1061

2 van Santvoort HC, Besselink MG, Bakker OJ et al. A step-up approach or open necrosectomy for necrotizing pancreatitis. NEJM 2010; 362: 1491-1502

3 Seifert H, Wehrmann T, Schmitt T et al. Retroperitoneal endoscopic debridement for infected peripancreatic necrosis. Lancet 2000; 356: $653-655$

4 Abdelhafez M, Elnegouly M, Hasab Allah MS et al. Transluminal retroperitoneal endoscopic necrosectomy with the use of hydrogen peroxide and without external irrigation: a novel approach for the treatment of walled-off pancreatic necrosis. Surg Endosc 2013; 27: 3911 - 3920

5 Siddiqui AA, Easler J, Strongin A et al. Hydrogen peroxide-assisted endoscopic necrosectomy for walled-off pancreatic necrosis: a dual center pilot experience. Dig Dis Sci 2014; 59: 687-690

\section{Bibliography}

Dol http://dx.doi.org/

10.1055/s-0034-1391244

Endoscopy 2015; 47: E68

(c) Georg Thieme Verlag KG

Stuttgart · New York

ISSN 0013-726X

\section{Corresponding author}

\section{Alberto Larghi, MD, PhD}

Digestive Endoscopy Unit

Catholic University

Largo A. Gemelli 8

Rome 00168

Italy

Fax: +39-06-30157220

albertolarghi@yahoo.it 